\title{
Just for the Image?
}

\author{
The Impact of Web 2.0 for Public Institutions \\ http://dx.doi.org/10.3991/ijet.v8iS1.2266
}

\author{
Stephanie B. Linek, Anneka Schafrick, Klaus Tochtermann \\ ZBW - Leibniz Information Centre of Economics, Kiel - Hamburg, Germany
}

\begin{abstract}
Web 2.0 is of growing importance and nowadays also a hot topic for public institutions. However, it is still an open question if users appreciate and recognize the merit of Web 2.0 applications in the context of public institutions. The presented paper describes first empirical findings on users' reactions on the linkage of a modern library 2.0 with Web 2.0 applications, namely the presence in social networks and the integration of blogs and wikis. The results showed that most users didn't recognize the benefit of Web 2.0 in the context of the homepage of a library 2.0. However, even though they didn't use the accordingly Web 2.0 links by themselves, they thought that the connection to Web 2.0 is a necessity for the image of a modern library. These findings imply that the connection to Web 2.0 is important for the image of a modern public institution but the surplus benefit has to be better communicated and to be made more visible on the conventional homepage in Web 1.0.
\end{abstract}

Index Terms-Web 2.0, social media, redesign homepage, public institutions, usability

\section{INTRODUCTION}

Applications of Web 2.0 are of growing importance. Especially social networks like Facebook or Google+ have a central role. Users spent more and more time on social platforms and use them for different purpose, e.g., for chatting instead of using a separate instant messaging application. Interestingly, for the teenage user population, the traditional divide indicators like Internet access or socioeconomic indicators of the parents are not significant indicators of the social media use [1]. It seems that social media are even more appealing compared to the traditional Web 1.0 and young people find a way to social network sites.

This paper describes an empirical study that provides first insights of the impact of Web 2.0 for public institutions. It starts with an introduction on general aspects of Web 2. 0 (user motivation, important features and potential barriers) and selected findings on social capital and public institutions in Web 2.0, that provide the background for the scope of the empirical study. Chapter two specifies the methodology of the study. In chapter three the results on the use of the Web 2.0 linkages (on a conventional homepage) are described. The paper closes with an overall discussion of the findings and recommendations for improvements and further developments.

\section{A. Users' motivations and usage patterns in Web 2.0}

Among others, one core characteristic of Web 2.0 is the user-generated content. In literature there exist different typologies depending on the different characteristics and the main purposes, e.g., blogs aim at content creation, social networking sites are mainly for community building and virtual game worlds are entertainment-oriented [2]. The multiple opportunities of social media are closely connected with the users' motivations. Accordingly, [3] analyzed the appeal of social media from a uses and gratification perspective. The uses and gratification approach [4] is a classical approach in media psychology that focuses on an active recipient who selects media and its contents for different purposes. The media behaviour is described by the psychological needs and motives of the individual (e.g., information seeking, escapism, entertainment). The uses and gratification model was originally formulated and applied for television behaviour and other traditional media [5]. Refined versions of the model were also successfully applied for new interactive media in the sense of Web 1.0 [6] [7] [8] [9]. However, like mentioned above one core characteristic of social media is the usergenerated content which opens up new possibilities for active user behaviour. Due to these new opportunities of participation, also new motives of the users can be addressed. While [10] identified information, entertainment and social aspects as the three main motives for the traditional Internet use (Web 1.0), the research on usergenerated content revealed six main motives, namely information, entertainment, social interaction, community development, self-expression and self-actualization [3] [11]. Some of these motives (e.g., information, entertainment) are analogous to the conventional Internet usage whereas some of the motives like self-expression and selfactualization are directly related to the special characteristics of Web 2.0.

Thereby, the users' motives are related to the users' activities and usage of social media. For example, [3] described three separate but interdependent usages of social media: Consuming (for information and entertainment), participating (for social interaction and community development), and producing (for self-expression and selfactualization). Other conceptualizations of possible motives for Web 2.0 usage are very similar to approach by [3]. For example, [12] described socializing, entertainment, self-status seeking, and information as main motives for the usage of social network sites. Reference [13] differentiated two groups of motives for user-generated content: rational motives (e.g., knowledge sharing and advocacy) and emotional motives (e.g., social connection). A user typology based on communication/participation patterns can be found by [14].

\section{B. Important features and potential barriers for Web 2.0 usage}

Even though the conceptualizations of users' motives and usage patterns outlined above are slightly different, 
they have one thing in common: the creative and productive user activities. This in turn means that the popularity of social media is closely connected with their handling or in other words their usability. The easier a Web 2.0 application is in its handling, the more the users will participate and produce content. Thereby, [3] underlined the importance of a good usability for all three forms of usage (consuming, participating and producing). This argumentation is in line with the Technology Acceptance Model (TAM) according to which the perceived usefulness and perceived ease of use are the critical variables for the adoption and use of a (new) technology [15] [16]. Thus, the widespread popularity of social media applications is also an indicator of their usability.

Another important feature is the user's control over the content. In the very beginning, most users are consumers of information and seek for entertainment. With some experience they start participating by interacting and sharing content with others. This can end up in producing, i.e., creating content. However, it is important to note, that only a minority of social media users participate or even create content or initiate other system activity [3].

When interacting with social media, users might face barriers inherent to the concrete type of social media and its community. For example, regarding public online group communication there are two main constraints [17]: critical mass and information overload. Critical mass regards to the necessity of a minimum of people that form the appropriate or sufficient group size for different activities, e.g., to solve a problem or to establish a sustainable discussion [18]. Information overload is a popular problem in mass communication when the incoming information exceeds the limited capacity of human information processing. Research has shown the so-called "magic number seven" (plus or minus two) of chunks or pieces of information one can process [19]. Thereby, selective attention is a necessary strategy in coping with the environment (see the filter model of attention by [20]). Based on these theoretical considerations [17] analysed over 2.65 million postings to 600 Usenet newsgroups in order to investigate the impact of individual information-overload coping strategies on mass communication. The results confirmed their three hypotheses: in overloaded mass communications users tend to answer mainly the simpler messages; with the increase of the overloaded mass communication, there is a higher probability that users stop the active participation; in overloaded mass communication, users will respond more likely with simpler messages. Besides such individual information-overload coping strategies also other kinds of filters can be applied. For example, for social network sites personalized recommender systems could be helpful technologies for supporting users in handling the information overload problem [21].

The new possibilities of usage comprise also special challenges for organizations and companies that try to be connected with the users and consumers on Web 2.0. Companies try to enhance the consumers' active involvement by offering possibilities to participate and contribute to the marketing content via social network sites like Facebook or by micro-blogging via e.g., Twitter. Thereby, it is implicitly assumed, that consumers are creative and active users [22]. However, like mentioned above, it was found that only a minority of users are producing content
[11] and consumers are less active than expected [17] [23] [24].

Based on the analysis of consumers' diaries on social media activities, [2] identified fifteen possible activities that can be used as possible strategies of companies to enhance consumers' active participation in the marketing segment. These strategies were ranking from creating games and online content to the provision of tools for facilitating daily practices. In line with [3] and the TAM [15], [2] stated "These games and the content must be easy to use, preferable free of charge, and entertaining in order to appeal to different users” (p. 363). Again, the perceived ease of use and the perceived usefulness are decisional. Or in other words: a good usability and a surplus merit it needed for attracting users or consumers to the social media instances of a company.

\section{Social media and social capital: Using Web 2.0 for public issues}

In the face of the growing importance of social media there is also an ongoing debate if and how, social networks influence the social capital and the political engagement of people [25] [26] [27]. On the one hand it is argued, that the social network sites offer new possibilities for political participation, for joining political motivated communities and for receiving more detailed information on civic issues. On the other hand, it is claimed, that social media lead to mainly loose connections with people and cause a decrease of political participation. Recently, [25] found that social networks can indeed foster political participation and social capital. Thereby it is important to note, that not the social media per se is decisional, but rather how the social media is used [28] [25].

A study of [29] on the usage of Twitter by non-profit organizations revealed that micro-blogging had three key functions "information" (i.e., providing information as one-way interaction), "community” (i.e., dialogue and community building by an interactive conversation), and "action" (i.e., the tweed aims at engaging the followers to do something). Even though most tweets of nonprofitorganizations could be classified as "information", the majority of nonprofit organizations were indeed using tweets of the categories "community" and "action". In the face of the available research and their own findings, [29] concluded that even though dialogue is not the main function of organizational communication in Web 2.0, it is a decisional factor for the strategically engagement of the stakeholders.

These examples underline that also in the context of public engagement not the social media channels per se, but rather the individual usage patterns and users' motivation are decisional for the benefit of social network sites. Thus, the crucial question is how the desired and appropriate usage patterns can be fostered, supported or initiated.

\section{Public institutions in Web 2.0}

Nowadays several public institutions are connected with Web 2.0. Via social networks, wikis and blogs they offer the opportunity for communication between the users or they provide additional specialized information and the latest news as a surplus benefit that goes (at least partly) beyond the scope of the official Web site in Web 1.0 . 
One example is the presence of universities on Facebook. A study by [30] provided first evidence how the possibility for students' pre-registration on Facebook influences the subsequent social network activities. The main motivation for students to use the pre-registration at Facebook was to find new friendships at the university and to stay in contact with the family and friends in their hometown. After pre-registration, Facebook was used to strengthen the new social network at university. As "social glue" it was more used for socializing than for working and studying at university. Thereby, Facebook was only one aspect in the student's social life. Additionally, it is worth noting, that in some cases Facebook was used for informal educational issues like organizing academic group meetings and that the majority of students was positive about the future use of Facebook for teaching and learning. Contrariwise to this positive tune, the majority of students didn't like to be contacted by the university staff for teaching, marketing, pastoral or administrative purposes. This might have to do with the image, main purpose and unwritten norms of Facebook [31] [32] [33]. Facebook is a social network for finding friends and social information exchange, but not for competition and work.

Until now there is only limited empirical evidence, if and how users appreciate Web 2.0 applications in the context of public institutions in general and libraries in specific. Do they welcome the new possibilities? Or is the connection with Web 2.0 detrimental for the image of a reputable library and similar public institutions? Another question in this context is what kind of surplus benefit a public institution can offer on the different Web 2.0 channels. The surplus benefit has not only to be in line with the image of the public institution, but also should consider the character and unwritten rules of the accordingly Web 2.0 application and the associated user expectations.

\section{E. Scope and background of the reported empirical study}

In the following selected findings are described that provide first insights, if and why users appreciate the connection of public institutions with Web 2.0. The reported study focused on the homepage of a library 2.0 (like defined by [34]), namely the ZBW - Leibniz Information Centre for (http://www.zbw.eu/e_about_us/e_library_profile.htm).

The ZBW is not only the world's largest library for economics, but also one of the leading information centres for the development and application of Web 2.0 for technological library innovations. Additionally, the ZBW offers numerous online services (e.g., EconBiz for literature search, EconStor for publishing working papers). The ZBW is also present in several popular Web 2.0 applications like Facebook, YouTube and Twitter. Also specialized internal Web 2.0 applications are available, for example the blog "ZBW Media Talk". The online services and the linkages to Web 2.0 can also be accessed via the homepage of the ZBW (http://www.zbw.eu). The web statistics indicate that the online services of the ZBW are very welcomed by the users. However, for the accordingly social media links on the homepage of the $\mathrm{ZBW}$ it is up to now unclear, if and how these links are used by the visitors of the conventional homepage in Web 1.0. Thus, this open question was included in a usability-study on the planned redesign of the homepage of the ZBW. Even though the finding are based on a small sample of people and should be considered as pilot data, the results provide a helpful first insight in the complexity of the research topic. Thereby it is important to note, that only the social media links on the homepage, but not the ZBW's actual presence in Web 2.0 (e.g., the ZBW-page in Facebook or the ZBW-channels in Twitter) was investigated in this study.

\section{PAPER-Prototying For Redesigning the HomePAGE} OF A LIBRARY 2.0

Like mentioned above, the presented findings are part of a usability-study on the redesign of the homepage of a library 2.0, namely the ZBW. Thereby, three different design versions (A, B, and C; see fig. 1, 2, and 3) of the new homepage of the ZBW were presented as paperprototypes. All three prototype-versions of the new homepage included several links to Web 2.0. Besides the links to popular social network sites, namely Facebook, Google+, Flickr, Slideshare and YouTube, two twitterchannels (“@zbw_news” and “@tochtermann”) and two internal blogs ("ZBW MediaTalk" and "WiWiWerkbank") were offered. (These links already existed on the ZBW's homepage. Due to recent developments, the Web 2.0 linkages on the actual version of the ZBW homepage were slightly changed.)

The study was conducted at the ZBW location in Hamburg with a German sample. Every test session was recorded by videotapes in the usability-laboratory of the ZBW. In order to lower test-anxiety, a short guidance through the usability-laboratory was provided. The usability-laboratory consisted of two rooms. The wall between the two rooms had a large one-way-mirror. In the testroom were three video-cameras and a microphone. For all test sessions a video-protocol was recorded. In the observation-room a second person (helper of the instructor) operated the video-cameras.

The paper-prototypes were tested by ten users (five male, five female; age between 21 and 30 years) who were already familiar with the ZBW. All participants were students, partly with experience in scientific work (PhD students). Each participant was tested in a single session. The test-session was guided by a female moderator (two different persons alternated to avoid instructor-effects). Additional one female helper was present (for assistance as a "human computer", see below). The original instructions, questions and tasks were presented in German. (Interested readers can contact the first author for the exact German wording and further details.)

The duration of the single test-sessions was between one and one and a half hour. During the test-session drinks and sweets were offered in order to foster motivation throughout the rather long test-session. After the testsession each participant received a 30,-€ voucher for a popular online shop as reward for his/her participation.

Before starting with the test, the participant was informed that the usability-department worked as an independent task force and critique was very welcomed, because every critique was helpful to improve the prototypes. Thereby, the participants were explicitly instructed that they should not be polite but honest and that there are no wrong or right answers. Additionally, participants were informed about privacy issues and that their answers and data are handled anonymously. 


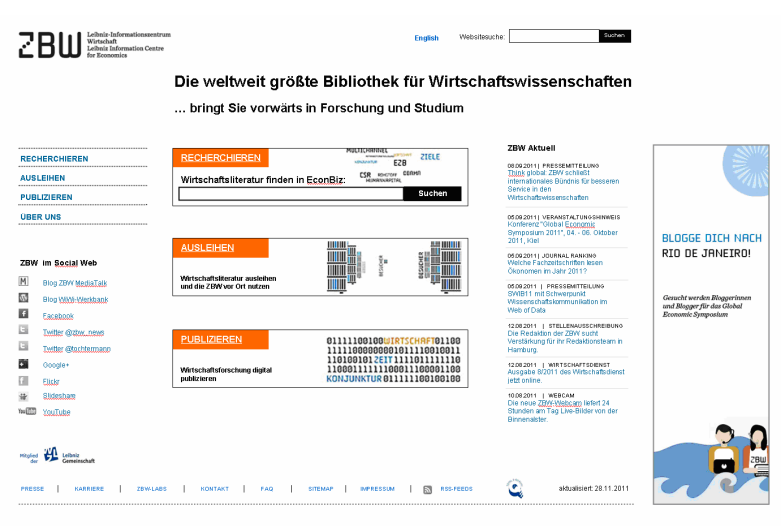

Figure 1. Design version A

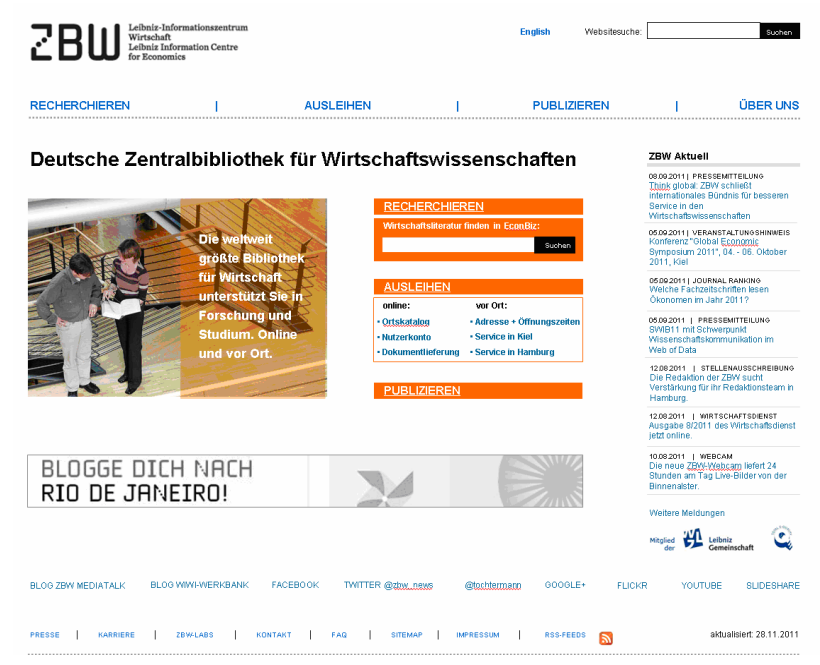

Figure 2. Design version B

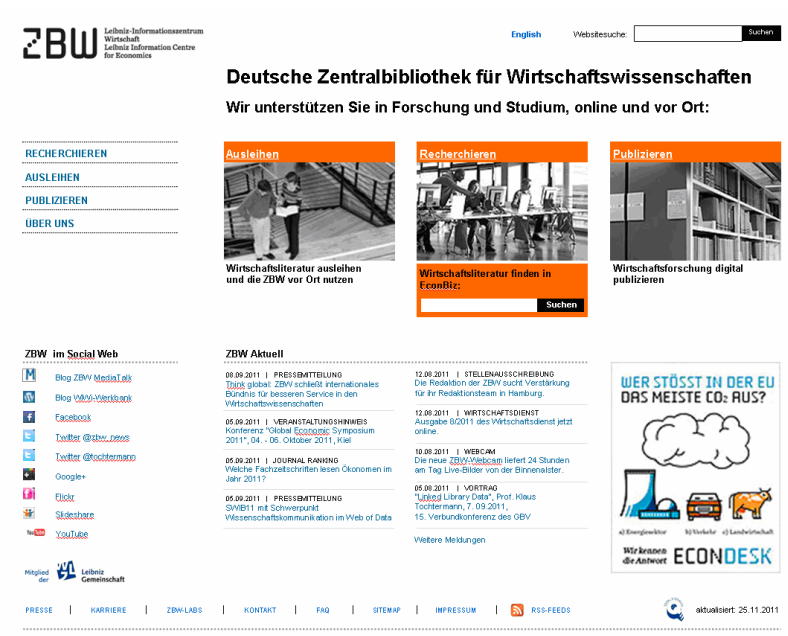

Figure 3. Design version C

The test-session had three main parts:

- Working with one chosen paper-prototype: Semistructured interview and usability tasks

- Advanced scribbling: Comparative analysis of the three design versions

- Handicraft-task: Creation of the user's wishhomepage
Throughout the complete test session, the "thinking aloud" method was applied, i.e., the participant had to verbalize what's was going through his/her head. Since "thinking-aloud" was a cornerstone of the study, each participant was trained in "thinking aloud" while working on a rebus. After the test-session each participant had to fill out a questionnaire for the assessment of control variables (age, gender, socio-economics, prior experiences with the ZBW and open remarks). In the following subchapters the three main parts are described in more detail.

\section{A. Working With One Chosen Paper-Prototype: Semi- Structured Interview and Usability Tasks}

At the very beginning of the test-session, it was asked for the user's first impression of the three design versions of the new homepage. Subsequently, the participant should spontaneously choose one of the prototypes (design $\mathrm{A}$, design $\mathrm{B}$, or design $\mathrm{C}$ ) that he/she preferred for the further working in the test-session. After selecting one prototype, the participants were asked four general questions:

- What do you think is this page made for?

- What do you think about this page? What do you notice?

- Do you think the slogan is appropriate for the ZBW?

- What do you think, you can make with this page? What do the single elements serve for?

The questions were also given in written form on small cards. In addition to these leading questions, the instructor asked for details and motivated the participant for further comments and critique. The general questions did not explicitly address the Web 2.0 linkages; however it was free to the participants to say spontaneously also some comments about the connection to Web 2.0.

After this semi-structured interview on the general impression of the new homepage-design, the participant had to manage seven usability-tasks with the selected homepage. Therefore also the subsequent pages of the homepage were available as paper-prototypes. When the participant "clicked" by finger pointing on a field, then the accordingly linked page was presented by a "human computer". The "human computer" was a female helping person, who was trained in the linkages of the paperprototypes. The procedure and method followed the usual standards of paper-prototyping [35]. The seven usability tasks regarded at:

- Literature search via the online service EconBiz

- Other options for finding important literature and related information on a topic

- Using the online-help EconDesk

- Finding information about online book lending

- Publishing via the online service EconStor

- Finding information about opening times and rooms at the location in Hamburg

- Finding information about internal research of the ZBW

The Web 2.0 linkages were not explicitly addressed by the usability tasks. However, the Web 2.0 links could be used to manage the task, e.g., as other options for finding related information on a topic which could also be on Facebook or Twitter. 


\section{B. Advanced Scribbling: Comparative Analysis of the Three Design Versions}

After the completion of the semi-structured interview and the seven usability-tasks, the participant received a print-out of each paper-prototype version (design $\mathrm{A}$, design $\mathrm{B}$, and design $\mathrm{C}$ ) and had to mark the single elements of the page with different colours: green for important elements, yellow for unnecessary elements and red for confusing elements. Additionally, a blue pen for writing comments was available. This method of "advanced scribbling" is also described in [36]. As a reminder, a small card with the meaning of the colours was placed besides the print-out.

\section{Handicraft-Task: Creation of the User's Wish- Homepage}

In the last part of the test session the participant had to tinker his/her wish-homepage of the ZBW (handicrafttask). The participant could use single elements of the three paper-prototypes or could create a completely different design. Therefore the participant received a blank sheet of paper, prints-outs of the three design versions (for cutting-out single elements) as well as different pens, a scissor and glue. The participants had a time-limit of fifteen minutes for this handicraft-task.

\section{RESULTS: LIBRARY 2.0 AND WEB 2.0}

Like mentioned above, the described study served as comparative usability-test of three design versions for the re-design of the ZBW's homepage. The overall analysis of the data resulted in several recommendations for improvement and a best-of-design of the new homage. In the following only the analyses and results are reported that are connected with the linkages to the Web 2.0.

In the context of the semi-structured-interview and the usability-task, the comments (direct answers and content of the thinking-aloud protocols) on the Web 2.0 linkages were analysed in a qualitative way. The main analyses of the linkages to Web 2.0 concentrated on the data of the advanced scribbling and the handicraft-task. For the advanced scribbling, it was calculated how many of the participants marked the Web 2.0 links in green (as important), in yellow (as unnecessary) or in red (as confusing). The analysis was done for each of the three design versions (A, B, and C) separately. For the handicraft-task, it was analysed how many of the participants integrate the Web 2.0 links in their own wish-homepage.

\section{A. Results of the Working With One Chosen Paper- Prototype}

For the spontaneous selection of a design version there was no clear favourite design version identifiable: two persons chose design A, four design B and four design $C$. Since all three design version included the analogous links to Web 2.0 the accordingly comments were analysed for all three design versions together.

The answers of the four general questions revealed that eight of the ten participants spontaneous recognized the links to Web 2.0. However, several of the links were partly unknown, namely the internal blogs and Slideshare. Even though most comments on the Web 2.0 links were positive in the sense that participants think it is important for a modern library 2.0 to use the modern Web 2.0 applications, the participants had no personal interest in using these Web 2.0 links of the ZBW. Regarding the banner with the announcement of a blog-competition, the participants (who had chosen design A or B) commented that they didn't know the purpose of the banner and that they didn't like it because it distract from the important contents of the homepage.

The usability-tasks revealed several usability-problems that had no relevance for the Web 2.0 linkages and thus are not described here. However, it is important to note, that for the solutions of the tasks the links to Web 2.0 were ignored by all participants.

\section{B. Results of the Advanced Scribbling}

The data of the advanced scribbling were analysed in order to identify important, unnecessary and confusing elements. Thereby, the frequency of green, yellow and red markings was calculated for each core element (e.g., main menu, headline, slogan, direct access to literature search). Fig. 4 shows a typical example of the advanced scribbling task. The thinking-aloud protocols were used for clarification if the marking was ambiguous (e.g., Blog-banner in fig. 4 was marked partly red and partly yellow.)

In the following, only the frequencies for the Web 2.0 links are reported. The accordingly quantitative results of the advanced scribbling are listed in Table 1 . The numbers show how many of the ten test persons marked the Web 2.0 links with the different colours. The participants were not forced to mark anything at all. Thus, the sum of green, yellow and red can be different from ten.

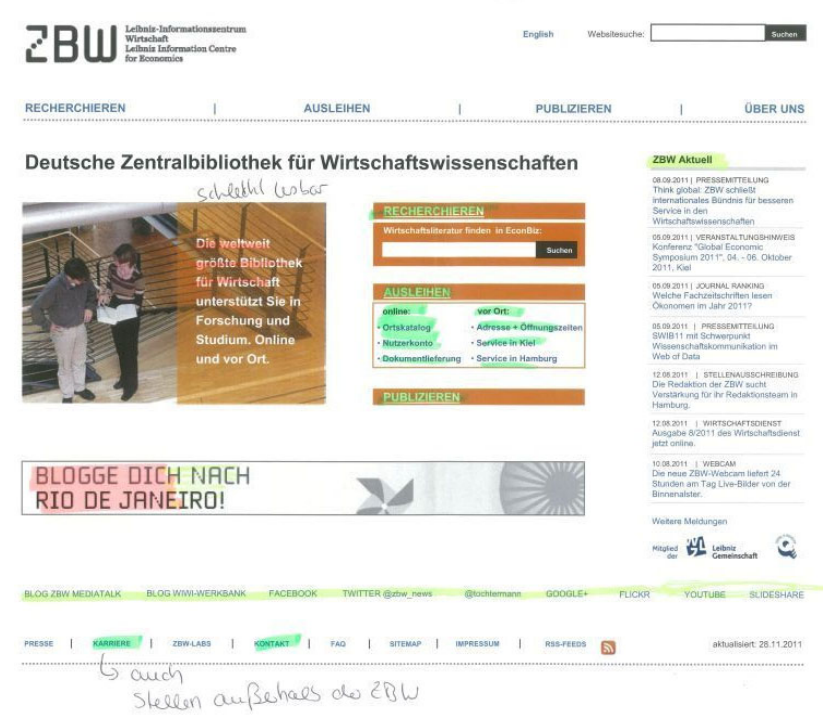

Figure 4. Typical example of the advanced scribbling

TABLE I.

ADVANCED SCRIBBLING: NUMBER OF PERSONS WHO MARKED THE WEB 2.0 LINKS IN THE DIFFERENT DESIGN VERSIONS

\begin{tabular}{|l|c|c|c|}
\hline \multirow{2}{*}{$\begin{array}{c}\text { Design } \\
\text { version }\end{array}$} & \multicolumn{3}{|c|}{ Marking of the Web 2.0 links } \\
\cline { 2 - 4 } & $\begin{array}{c}\text { green } \\
\text { (important) }\end{array}$ & $\begin{array}{c}\text { yellow } \\
\text { (unnecessary) }\end{array}$ & $\begin{array}{c}\text { red } \\
\text { (confusing) }\end{array}$ \\
\hline Design A & 1 & 7 & 1 \\
\hline Design B & 3 & 4 & 2 \\
\hline Design C & 1 & 7 & 0 \\
\hline
\end{tabular}

The ten test persons were not forced to mark anything at all; thus, the sum is different from ten 
The data showed that most users marked the links to Web 2.0 as unnecessary. Only a minority marked the Web 2.0 links in green, i.e. as important. The participants commented (by thinking aloud), that the Web 2.0 links are for themselves unimportant. They reported that they never used the Web 2.0 links on the current homepage of the ZBW. Some of the Web 2.0 applications were not even known by the users.

\section{Results of the Handicraft-Task}

The results of the handicraft-task showed that the majority, i.e., seven of the ten test persons, integrate the Web 2.0 links in their wish-homepage. Three of the ten participants integrate the banner with the blog-competition (from design A, partly in a smaller version). Only two persons had neither the social media links nor the banner with the blog-competition in their wish-homepage. Fig. 5 shows a typical example. Please note that this example of a wishhomepage in fig. 5 (including Web 2.0 links) was done by the same participant who marked the Web 2.0 links in yellow (as unnecessary) in fig. 4.

While integrating the Web 2.0 links in their wishhomepage, these people argued (by thinking aloud) that even though they never personally used the Web 2.0 links or the application itself, it is essential for a modern library 2.0 to have such linkages to Web 2.0.

\section{Discussion AND OUTLOOK}

The reported investigation is only a first pilot study with a small sample of people. However, even for such a small sample of ten participants, the findings illustrate the benefit of a multi-method approach that provides deeper insights and offers the possibility for an adequate interpretation of the results. The results of the advanced scribbling showed that at the links with Web 2.0 on the homepage of a library 2.0 had no personal importance for the user. Contrariwise, the results of the handicraft-task implied that the linkage to Web 2.0 is a necessity for a modern library 2.0. On the first sight, these results seemed somehow contradicting. However, a look at the thinking aloud protocols provided a reasonable interpretation. Even though the Web 2.0 links are also integrated in the existing current version of the homepage of the $\mathrm{ZBW}$, most users never used them. They did not even click them, because they assume, that it is of no personal benefit. On the other hand, most users recognized that Web 2.0 is a hot topic in modern time. For the handicraft task, the participants explicitly stated that the linkage to Web 2.0 is a necessity for a modern library 2.0 (no matter what content is behind the link), however the participants didn't think it has a personal benefit for them. Thus, the overall interpretation of the findings leads to the conclusion, that Web 2.0 is indeed important for a public institution like a library 2.0. However, it is not sufficient to have a linkage to Web 2.0. Rather, the surplus merit of using the linkage of a library 2.0 with Web 2.0 has to be communicated to the users.

This interpretation is in line with the finding, that the participants ignored the Web 2.0 links while working on the usability tasks. In the second usability-task it was asked if the participant believed that the ZBW can provide additional help beside the literature search service EconBiz. Some of the links to Web 2.0 are apt for providing additional help, e.g., by the additional information pre-

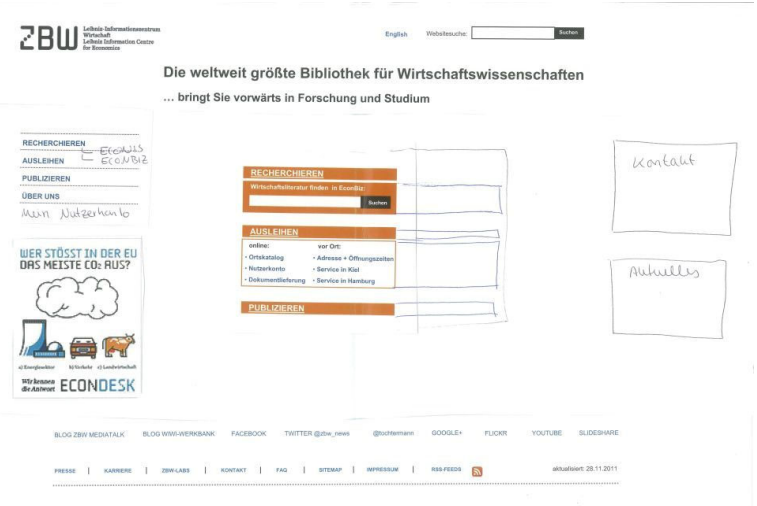

Figure 5. Typical example of the handicraft-task

sented on Facebook, Twitter or in the Social Media Blog. Additionally, a discussion with the ZBW community at Facebook might also be helpful for supporting and enhancing the conventional literature search. Even though, this is partly already implemented, the users apparently didn't recognize it until now. From a uses and gratification perspective this means, the users of the conventional homepage in Web 1.0 didn't recognize that the additional presence in Web 2.0 offer content that could be useful for their own purposes and therefore, the users lack motivation to visit the accordingly links.

Thus, besides pure image reasons, a public institution have two consider two main points when using Web 2.0 applications: First, a surplus benefit beyond the scope of the official Web Site in Web 1.0 has to be offered. Second, the surplus benefit has to be communicated to the community in order to build up the user's motivation to visit and to use the accordingly linkages to Web 2.0.

In the case of the ZBW the current traffic on e.g., the ZBW's page on Facebook implies that there is indeed a big surplus benefit beyond the Web 1.0. In 2012 there are about 1300 visitor per month on the Facebook timeline. The posts in Facebook are read between 400 and 1000 times within 28 days (depending on the content). However, only about 60 persons of the over thousand visitors of the Facebook timeline are coming from the ZBW's homepage in Web 1.0. This is even more astonishing since the ZBW's Web site has about 30000 visitors per month (the homepage with the linkage to Facebook has about 20000 visitors per month). Taking these statistics together, it seems that the surplus benefit in Web 2.0 is very welcomed in the Web 2.0 community. However, the users of the conventional homepage in Web 1.0 don't recognize the surplus benefit. Or in other words: The ZBW's users in Web 1.0 are still a sleeping potential for the Web 2.0 application. Thus, the main challenge is to communicate the surplus benefit of the ZBW in Web 2.0 also to the users of the conventional homepage in Web 1.0.

Additionally, there are also other reasons thinkable why many users don't even try the links to Web 2.0. One possible explanation could lie in information overload [17]. Maybe, the ZBW's homepage and the professional search tool provides too many or too detailed information about the search topic. This could also be related to the found usability problems (e.g., difficulties in interpreting the icons for the availability of literature; problems in identifying the chat-box of the online-help). As the usability of the ZBW's homepage will be improved there will be more cognitive resources available and the willingness 
and curiosity of people to try the Web 2.0 linkages may rise. This is also in line with the notion of [3], that good usability is an entrance condition for using Web 2.0 applications. For public institutions (and other organizations), that are present in Web 2.0, the usability of the own homepage act as signboard for the usefulness of the accordingly links in Web 2.0. Or in other words: If you annoy the users on the homepage in Web 1.0 with low usablility, then they are not interested in getting more of the same confusing contents in Web 2.0. That means the users' expectations have to be addressed or modified. Thereby it is important to note, that users have not only expectations about the public institution but also about the Web 2.0 applications. When using a Web 2.0 application like Facebook, the communicator (i.e. the public institution) has to be aware of the unwritten rules [31]. Similar, the communicated contents (or other surplus benefits) have to be in line with the possibilities of the selected Web 2.0 application. According to the Media Richness Theory a complex issue needs a richer media [37]. For example, tweets are not apt for holding a lecture. However, tweets might be very usefully for the communication during a lecture.

Another important point for the rare usage of Web 2.0 may lie in the lack of a critical mass of the community [18]. Imagine for example, that a public institution offers an expert-moderated discussion platform on Facebook. In this case it is decisional to have a critical mass of users as discussion participants. Especially for small public institutions this could be problematic. Thus, it might be helpful to collaborate in Web 2.0 with other public institutions that have a similar or complementary topic. Additional, it is reasonable to encourage users' activities. This could be done by rewarding contributions. Popular techniques for rewarding are for example the provision of a monthly activity index or a status as "expert" or "mentor". Other factors for enhancing users activities are e.g., support for browsing, information about the community or group, direct comments and provocative statements of moderators [24].

Taking together, the main recommendations for improving the popularity of public institutions in Web 2.0 are:

- Providing a surplus benefit on the Web 2.0 that goes beyond the scope of the official homepage in Web 1.0, e.g., enabling expert-moderated discussions.

- Communicating the surplus benefit on the Web 2.0 to the community, especially the community in Web 1.0, and to important stakeholders.

- Improving the usability of the public institution's homepage in Web 1.0, because it acts as signboard for the usability and usefulness of the linkages to Web 2.0.

- Providing contents and activities that are in line with the users' expectations about the concrete Web 2.0 application.

- Enabling a critical mass of users by community building and collaboration with similar or complementary public institutions on Web 2.0.

- Encouraging users' activities by rewarding or other techniques.

The list of recommendations is neither complete nor exhaustive. The recommendations need more empirical evidence and the effectiveness and efficiency of the single points have to evaluated and validated. However, the findings of the reported study and the given suggestions for improvement can be seen as a good starting point for further activities of public institutions in the Web 2.0 and more systematic research in the future.

\section{REFERENCES}

[1] J. Ahn, "Digital divides and social network sites: Which students participate in social media?” Journal of Educational Computing Research, vol. 45(2), pp. 147-163, 2011. http://dx.doi.org/ 10.2190/EC.45.2.b

[2] K. Heinonen, "Consumer activity in social media: Managerial approaches to consumers' social media behaviour," Journal of Consumer Behavior, vol. 10, pp. 356-364, 2011. http://dx.doi.org/10.1002/cb.376

[3] G. Shao, "Understanding the appeal of user-generated media: a uses and gratification perspective," Internet Research, vol. 19, pp. 7-25, 2009. http://dx.doi.org/10.1108/10662240910927795

[4] E. Katz, J. Blumler, and M. Gurevitch, "Utilization of mass communication by the individual," in The uses of mass communications: Current perspectoves on gratifications research, J. Blumler and E. Katz, Eds., Sage, Beverly Hills, CA, pp. 19-32, 1974.

[5] J. Conway and A. Rubin, "Psychological predictors of television viewing motivation," Communication Research, vol. 18 (4), pp. 443-463, 1991. http://dx.doi.org/10.1177/009365091018004001

[6] J. Dimmick, S. Kline, and L. Stafford, "The gratification niches of personal e-mail and the telephone,” Communications Research, vol. 27 (1), pp. 227-248, 2000. http://dx.doi.org/10.1177/ 009365000027002005

[7] D. Ferguson and E. Perse, "The world wide web as a functional alternative to television," Journal of Broadcasting and Electronic Media, vol. 44(2), pp. 155-174, 2000. http://dx.doi.org/ 10.1207/s15506878jobem4402_1

[8] R. LaRose, D. Mastro, and M. Eastin, “Understanding Internet usage: a social-cognitive approach to uses and gratifications," Social Science Computer Review, vol. 19(4), pp. 395-413, 2001. http://dx.doi.org/10.1177/089443930101900401

[9] T. Ruggiero, "Uses and gratifications theory in 21th century," Mass Communication \& Society, vol. 3(1), pp. 3-37, 2000. http://dx.doi.org/10.1207/S15327825MCS0301_02

[10] T. F. Stafford, M. Stafford, and L. L. Schkade, "Determining uses and gratifications for the internet," Decision Sciences, vol. 35(2), pp. 259-288, 2004. http://dx.doi.org/10.1111/j.00117315.2004.02 524.X

[11] C. Courtois, P. Mechant, L. De Marez, and G. Verleye, "Gratifications and seeding behavior of online adolescents," Jouornal of Computer-Mediated Communication, vol. 15, pp. 109-137, 2009. http://dx.doi.org/10.1111/j.1083-6101.2009.01496.x

[12] N. Park, K. F. Kee, and S. Valenzuela, "Being immersed in social networking environment: Facebook Groups, Uses and gratifications, and social outcomes," Cyberpsychology \& Behavior, vol. 12(6), pp. 729-733, 2009. http://dx.doi.org/10.1089/cpb.2009.0003

[13] S. Krishnamurthy and W. Dou, “Advertising with user-generated content: A framework and research agenda,” Journal of Interactive Advertising, vol. 8(2), pp. 1-7, 2008.

[14] K. de Valck, G. van Bruggen, and B. Wierenga, "Virtual communities: A marketing perspective,” Decision Support Systems, vol. 47, pp. 185-203, 2009. http://dx.doi.org/10.1016/j.dss.2009.02.008

[15] F. D. Davis, R. P. Bagozzi, and P. R. Warshaw, "User acceptance of computer technology: A copmparison of two theoretical models,” Management Science, vol. 35, pp. 982-1002, 1989. http://dx.doi.org/10.1287/mnsc.35.8.982

[16] V. Venkatesh, "Technology acceptance model 3 and a research agenda on interventions,” Decision Sciences, vol. 39(2), pp. 273315, 2008. http://dx.doi.org/10.1111/j.1540-5915.2008.00192.x

[17] Q. Jones, G. Ravid, and S. Rafaeli, "Information overload and the message dynamics of online interaction spaces," Information System Research, vol. 15(2), pp. 194-210, 2004. http://dx.doi.org/10.1287/isre.1040.0023

[18] M. L. Markus, "Towards a "critical mass" theory of interactive media: Universal access, interdependence and diffusion,” Com- 


\section{Just FOR THE IMAgE? THE IMPACT OF Web 2.0 FOR PUBLIC INSTITUTIONS}

munication Research, vol. 14, pp.491-511, 1987 http://dx.doi.org/10.1177/009365087014005003

[19] G. A. Miller, "The magical number seven, plus or minus two: Some limits on our capacity to process information,” Psychological Review, vol. 63, pp. 81-97, 1956. http://dx.doi.org/ $10.1037 / \mathrm{h} 0043158$

[20] D. Broadbent, Perception and communication. London, uk: Pergamon Press, 1958.

[21] X. Zhou, Y. Xu, Y. Li, A. Josang and C. Cox, "The state-of-the-art in personalized recommender systems for social networking," Artificial Intelligence Review, vol. 37, pp.119-132, 2012. http://dx.doi.org/10.1007/s10462-011-9222-1

[22] P. R. Berthon, L. Pitt, and Campbell, C, "When customers create the ad," California Management Review, vol. 50(4), pp. 6-30, 2008. http://dx.doi.org/10.2307/41166454

[23] E. Joyce and R. E. Kraut, "Predicting continued Participation in Newsgroups," Journal of Computer-Mediated Communication, vol. 11(3), pp. 723-747, 2006. http://dx.doi.org/10.1111/j.10836101.2006.00033.x

[24] J. Preece, B. Nonnecke, and D. Andrews, "The top 5 reasons for lurking: improving community experiences for everyone," Computers in Human Behavior, vol. 20(2), pp. 201-223, 2004. http://dx.doi.org/10.1016/j.chb.2003.10.015

[25] H. Gil de Zúñiga, N. Jung, and S. Valenzuela, „Social media use for News and individuals' social capital, civic engagement and political participation,” Journal of Computer-Mediated Communication, vol. 17, pp. 319-336, 2012. http://dx.doi.org/10.1111/j.10836101.2012.01574.X

[26] W. L. Bennett, "Changing citizenship in the digital age," in Civic life online: Learning how digital media can engage youth, W. L. Bennett, Ed., The MIT Press: Cambridge, MA, pp. 1-24, 2008.

[27] I. Himelboim, "Reply distribution in online discussions: a comparative network analysis of political and health newsgroups," Journal of Computer-Mediated Communication, vol. 14, pp. 156177, 2008. http://dx.doi.org/10.1111/j.1083-6101.2008.01435.x

[28] H. Gil de Zúñiga, „Blogs, journalism and political participation,” in Journalism and Citiztenship: New agendas in communication, Z. Papacharissi, Ed.,Routledge: New York, pp. 108-123, 2009.

[29] K. Lovejoy, and G. D. Saxton, "Information, community, and action: How nonprofit organizations use social media,” Journal of Computer-Mediated Communication, vol. 17, pp. 337-353, 2012. http://dx.doi.org/10.1111/j.1083-6101.2012.01576.x
[30] C. Madge, J. Meek, J. Wellens, and T. Hooley, "Facebook, social integration and informal learning at university: 'It is more for socialising and talking to friends about work than for actually doing work'," Learning, Media, and Technology, vol. 34(2), pp. 141-155 , 2009. http://dx.doi.org/10.1080/17439880902923606

[31] C. McLaughlin, and J. Vitak, "Norm evolution and violation on Facebook,” New Media and Society, vol. 14(2), pp. 299-315, 2012. http://dx.doi.org/10.1177/1461444811412712

[32] C. Ross, E. S. Orr, M. Sisic. J. M. Arsenault, M. G. Simmering, and R. R. Orr, „Personality and motivations associated with Facebook use,“ Computers in Human Behavior, vol. 25, pp. 578-586 ,2009. http://dx.doi.org/10.1016/j.chb.2008.12.024

[33] K. A. Karl, and J. V. Peluchette, “'Friending` professors, parents and bosses: a Facebook connection conundrum,"Journal of Education for Business, vol. 86, pp. 214-222, 2011. http://dx.doi.org/10.1080/08832323.2010.507638

[34] J. M. Maness, "Library 2.0 theory: Web 2.0 and its implications for libraries,"Webology, vol.3(2), online available: http://www.webology.org/2006/v3n2/a25.html, 2006.

[35] C. Snyder, Paper prototyping. The fast and easy way to design and refine user interfaces. San Francisco: Elsevier, 2003.

[36] S. B. Linek and K. Tochtermann, "Assessment of usability benchmarks: combining standardized scales with specific questions," International Journal of Emerging Technologies in Learning, vol. 6(4), pp. 56-64, 2011.

[37] R. L. Daft and R. H. Lengel, "Organizational information requirements, media richness and structural design,” Management Science, vol. 32 (5), pp. 554-571, 1986. http://dx.doi.org/ $\underline{10.1287 / \text { mnsc.32.5.554 }}$

\section{AUTHORS}

Stephanie B. Linek, Anneka Schafrick, and Klaus Tochtermann are with Research \& Usability, ZBW Leibniz Information Centre of Economics, Kiel - Hamburg, Germany, s.linek@zbw.eu.

This article is an extended and modified version of a paper presented at the International Conference on Interactive Collaborative Learning (ICL2012), held 26 - 28 September 2012, in Villach, Austria. Received 13 September 2013. Published as resubmitted by the authors 3 December 2012. 